\title{
Desempenho agronômico de cultivares de mandioca de mesa em ambiente do cerrado
}

Rogério Borges de Oliveira Paz ${ }^{1}$, Claudio Hideo Martins da Costa ${ }^{1}$, Eduardo Alano Vieira ${ }^{2}$, Mirelle Vaz Coelho ${ }^{1}$ Simério Carlos da Silva Cruz ${ }^{1}$, Lucas Bastos Machado ${ }^{1}$

${ }^{1}$ Universidade Federal do Jataí - UFJ, GO. ${ }^{2}$ EMBRAPA CERRADOS. E-mail

\section{Resumo}

A mandioca de mesa é cultivada em todo território brasileiro, porém precisa ser melhor estudada na região do Cerrado, que apresenta potencial para seu cultivo. Objetivou-se com este trabalho avaliar o comportamento das cultivares de mandioca de mesa em solo de Cerrado por duas safras. Os experimentos foram realizados nas safras agrícolas de 2016-2017 e 2017-2018, em Jataí-GO, com seis cultivares. Utilizouse delineamento em esquema fatorial, sendo 6 cultivares e 2 épocas de plantio, com três repetições. Foram avaliadas: número de hastes, diâmetro de hastes, altura da primeira ramificação, altura de plantas, número de raízes por planta, comprimento de raiz, diâmetro de raiz, massa fresca de raiz, massa fresca da parte aérea, índice de colheita e tempo de cozimento. Houve interação entre as fontes de variação para massa fresca de raízes e massa fresca da parte aérea. A cultivar BRS 399 obteve melhor produtividade de raiz nas duas safras. As cultivares BRS 399, BRS 400, BRS 401 e IAC 576/70 aumentaram a massa fresca da parte aérea da primeira para segunda safra. O índice colheita das cultivares BRS 400 e BRS 401 reduziram do primeiro para segundo ano de cultivo. Conclui-se que apresentaram melhor desempenho agronômico no ano agrícola 2016/2017 as cultivares BRS 397, BRS 398, BRS 399 e IAC 576/70, por sua vez, no ano agrícola 2017/2018 as cultivares BRS 397, BRS 399 e BRS 400 apresentaram os melhores resultados. As cultivares BRS-397 e BRS-399 apresentaram comportamento agronômico mais estável que as demais nas duas safras. Palavras - chave: Manihot esculenta Crantz; produtividade de raiz; safra.

\section{Agricultural performance of sweet cassava cultivars in cerrado environment}

\begin{abstract}
Sweet cassava is cultivated throughout Brazil, but needs to be better studied in the Cerrado region that has potential for its cultivation. The objective of this work was to evaluate the performance of sweet cassava cultivars in Cerrado soil during two growing season. The experiments were carried in 2016-2017 and 20172018 with six cultivars, in Jataí-GO. The experimental design was factorial scheme 6 × 2, being 6 cultivars and two growing season, with three replications. The following evaluations were carried out: number of stems, stem diameter, height of the first branch, height of plants, number of roots per plant, length of roots, diameter of roots, weight of fresh roots, weight of fresh roots, weight of fresh shoots, harvest index and cooking time. The cultivar BRS 399 had better root yield in the two crop years. The cultivars BRS 399, BRS 400, BRS 401 and IAC 576/70 increased the plant shoot weight from the first to the second growing season. The harvest index of cultivars BRS 400 and BRS 401 decreased from the first to the second growing season. It was concluded that the cultivars BRS 397, BRS 398, BRS 399 and IAC 576/70 presented the best agronomic performance in the 2016/2017 growing season, in turn, in the growing season $2017 / 2018$, the cultivars BRS 397, BRS 399 and BRS 400 presented the best results. The cultivars BRS-397 and BRS-399 showed more stable agronomic behavior than the others.
\end{abstract}

Keywords: growing season; Manihot esculenta Crantz; root productivity. 


\section{Introdução}

O Brasil é o quinto maior produtor de mandioca (Manihot esculenta Crantz) do mundo com a produção acima de 17,6 milhões de toneladas produzidos em 1,2 milhões de hectares, ficando atrás de Nigéria, Tailândia, Congo e Gana (FAO, 2020). Em 2015, a mandioca foi o quinto setor da produção agrícola mais importante do Brasil, com uma renda bruta de 8,2 bilhões de reais (CONAB, 2017). Cultivada em todo território nacional, sendo sua maior concentração nas regiões Norte e Nordeste, representado $59 \%$ da produção, seguida pelas regiões Sul e Sudeste com 24 e 10,9\%, respectivamente. A região Centro-Oeste, onde predomina o Bioma Cerrado, apresenta 6,1\% da produção nacional (SOUSA et al., 2017).

Também classificada pela sua importância alimentar e consumida em todo o mundo, aproximadamente 800 milhões de pessoas (SARAVANAN et al., 2016), devido ao rico conteúdo de energia, fácil cultivo, pouca incidência de pragas e doenças, tolerância à seca e aos solos ácidos e flexibilidade de colheita, denominando-a como uma cultura fundamental para a segurança alimentar em alguns países (VENTURINI et al., 2015).

Os sistemas de produção de mandioca de mesa no Cerrado têm maior proximidade com a agricultura familiar, visto que apresenta uma produção em pequena escala, utiliza pouca tecnologia e capital, trabalha com a mão de obra familiar e tem sua comercialização concentrada no mercado local (REINHARDT, 2013). A produção para mesa está se desenvolvendo em meio aos horticultores dos cinturões verdes das grandes cidades, atendendo à demanda pelo produto e resultando em lucratividade da lavoura (AGUIAR et al., 2013). Por outro lado, o cultivo é fundamental nos sistemas de rotação ou sucessão com outras culturas agrícolas (RINALDI et al., 2015).

Cultivares de mandioca de mesa possui baixo teor de ácido cianídrico (AGUIAR et al. 2011) e apresentam características que agregam qualidade, com colorações, tempo de cocção, ausência de fibras e tempo maior de prateleira quando resfriadas ou congeladas (FIALHO; VIEIRA, 2013). É bastante comercializada em in natura ou minimamente processada, refrigerada, congelada, pré-cozida ou em "chips", facilitando seu preparo (AGUIAR et al., 2013).

A introdução de novas variedades tal como o desenvolvimento de técnicas apropriadas ao cultivo desta espécie sob os mais variados sistemas de produção, são desafios para melhorar a produtividade e sua qualidade. No entanto, são necessários trabalhos de divulgações para com os produtores, desenvolvimento de estudos para avaliação e identificação de cultivares mais indicados para cultivo, apresentando resultados como produção por área, tempo de colheita estendido e aceitação do mercado.

Deste modo, fazer com que o cultivo deixe de ser apenas a manutenção de uma cultura centenária de subsistência para se transformar em um ótimo negócio, capaz de atender não apenas a demanda local, mas também abranger outras regiões, além de gerar emprego e melhoria da qualidade de vida das pessoas que estão envolvidas com esta atividade.

Objetivou-se avaliar o desempenho agronômico das cultivares lançadas no ano de 2015, tais como: BRS 397, BRS 398, BRS 399, BRS 400 e BRS 401, cultivadas por duas safras em ambiente de Cerrado.

\section{Material e Métodos}

O experimento foi instalado e conduzido na Universidade Federal de Goiás, Regional Jataí - Unidade Jatobá, localizada no município de Jataí (GO), localizado nas coordenadas geográficas $51^{\circ} 42^{\prime} 52^{\prime \prime}$ Oeste e $17^{\circ} 55^{\prime} 36^{\prime \prime}$ Sul, com altitude aproximada de 679 metros. O clima predominante na região é do tipo Aw de acordo com a classificação de Köeppen, que se caracteriza como tropical de altitude, com inverno seco e verão quente e chuvoso (CARDOSO JUNIOR et al., 2015). Os dados de temperatura média e precipitação média seguem representados nas figuras $1 \mathrm{~A}$ e $1 \mathrm{~B}$ para os períodos de outubro de 2016 a setembro de 2017 e de outubro de 2017 a setembro de 2018, respectivamente. 
Figura 1. Precipitação pluvial e temperaturas médias durante a condução dos experimentos coletados no Banco de Dados Meteorológicos para Ensino e Pesquisa (BDMEP) em Jataí-GO.

A

Cultivo 2016/2017

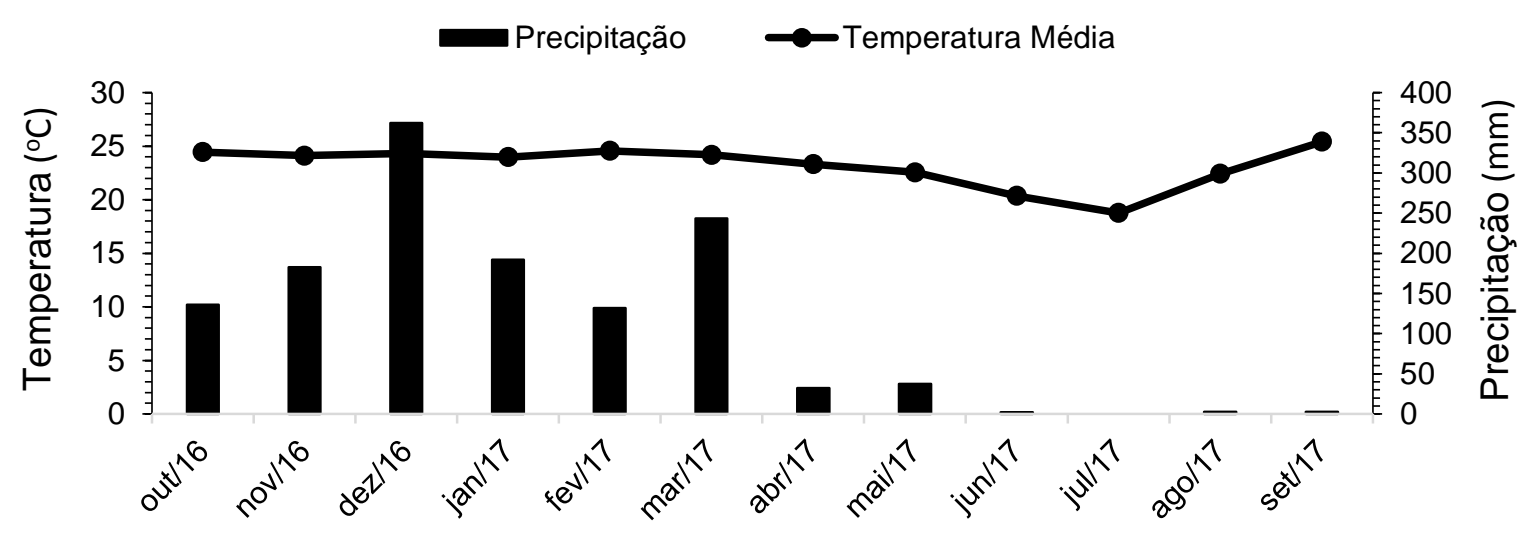

B

Cultivo 2017/2018

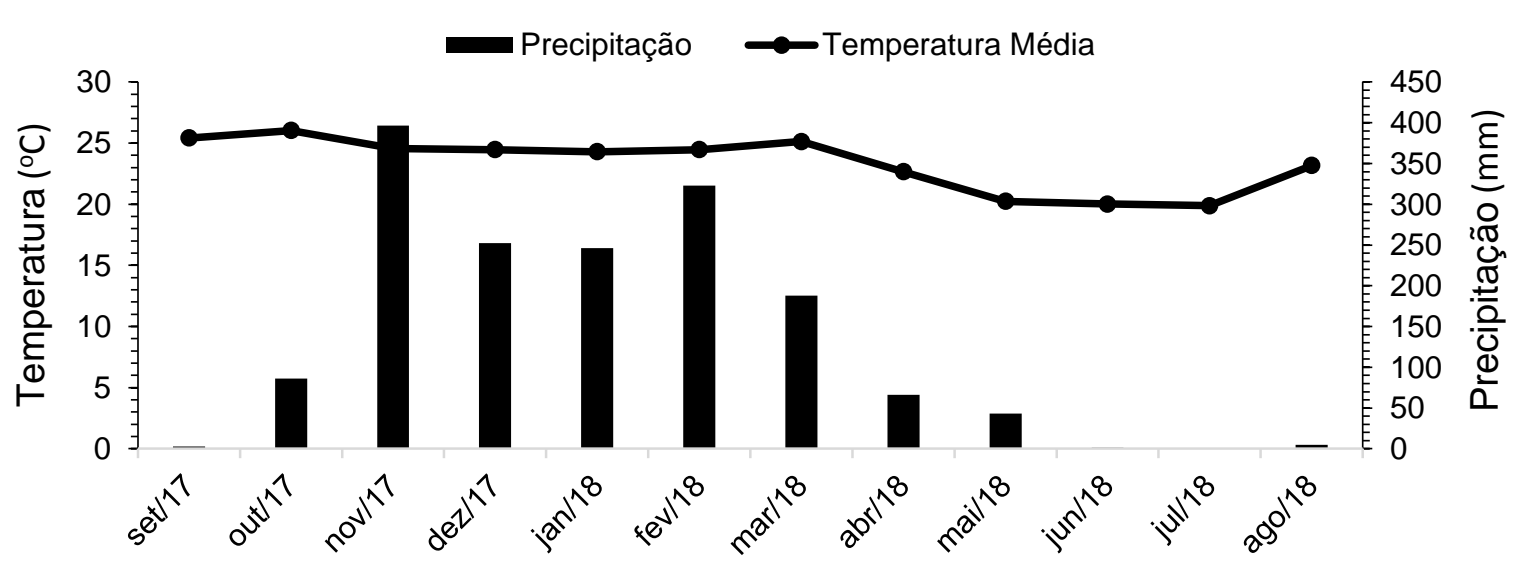

O solo da área experimental é classificado caracterização química inicial do solo, cujo os como Latossolo Vermelho Distroférrico, com resultados estão apresentados na Tabela 1.

textura argilosa (SANTOS, 2018). Antes da

instalação do experimento foram coletadas

amostras na camada de $0-20 \mathrm{~cm}$ para

Tabela 1. Caracterização química do solo na camada de $0-20 \mathrm{~cm}$ da área do experimental em Jataí - GO, 2016

\begin{tabular}{|c|c|c|c|c|c|c|c|c|c|c|c|}
\hline $\mathrm{pH}$ & MO & $\mathrm{P}_{\text {(resina) }}$ & $S$ & $\mathrm{Al}^{+3}$ & $\mathrm{H}+\mathrm{Al}$ & K & $\mathrm{Ca}$ & $\mathrm{Mg}$ & SB & СТC & V\% \\
\hline $\mathrm{CaCl}_{2}$ & $\mathrm{~g} \mathrm{dm}^{-3}$ & $\mathrm{mg} \mathrm{dm}^{-3}$ & --- & ------. & --------- & imolc & -3 & ----- & -.-... & & \\
\hline 5.0 & 39 & 16 & 22 & 1 & 29 & 1.76 & 17 & 11 & 30 & 59 & 51 \\
\hline
\end{tabular}

As cultivares de mandioca de mesa utilizadas foram: BRS 397, BRS 398, BRS 399, BRS 400, BRS 401, que foram lançadas pela Embrapa Cerrados (Planaltina-DF) em 2015 e a IAC 576/70 do Instituto Agronômico de Campinas, já cultivada no cerrado (FIALHO et al., 2009; VIEIRA et al., 2018). A área de plantio possui histórico de cultivo de soja/milho, no tocante não houve necessidade do uso de arado e grade para o preparado do solo para o plantio. Sendo assim, feito 01 pulverização com herbicida glifosato ( $\mathrm{N}$ (fosfonometil)glicina) $4 \mathrm{~L} \mathrm{ha}{ }^{-1}$, para o controle de plantas espontâneas. Após 02 semanas do controle de plantas daninhas, foi realizado a abertura dos sulcos de plantio com a utilização do sulcador, regulado para obter $10 \mathrm{~cm}$ de 
profundidade.

O delineamento utilizado foi em blocos ao acaso, com três repetições em esquema fatorial, sendo os fatores cultivares $x$ safras. As parcelas de $48 \mathrm{~m}^{2}$ foram constituídas por 04 fileiras de 10 metros de comprimento, espaçadas de 1,2 metros por 0,8 metros entre covas e 02 metros entre parcelas. $\mathrm{Na}$ adubação de plantio foi utilizada $80 \mathrm{~kg} \mathrm{ha}^{-1}$ de $\mathrm{P}_{2} \mathrm{O}_{5}$ (superfosfato simples $18 \%$ de $\mathrm{P}_{2} \mathrm{O}_{5}$ ), $60 \mathrm{~kg} \mathrm{ha}^{-1}$ de $\mathrm{K}_{2} \mathrm{O}$ (cloreto de potássio $58 \%$ de $\mathrm{K}_{2} \mathrm{O}$ ) incorporados no sulco de plantio e $40 \mathrm{~kg} \mathrm{ha}^{-1}$ de nitrogênio (uréia $46 \%$ de N) aos 30 dias após o plantio, de acordo com Sousa e Lobato (2004) e Sousa et al. (2017).

Os plantios da primeira e segunda safra ocorreram em 03 novembro de 2016 e 15 de outubro de 2017, respectivamente. Para o controle das plantas daninhas foram realizadas capinas manuais quando necessário e não houve a necessidade do uso de produtos fitossanitários para o controle de pragas e doenças.

Aos nove meses após o plantio, foi realizada a colheita e as avaliações experimentais em seis plantas das duas fileiras centrais, considerada área útil de $5,76 \mathrm{~m}^{2}$ de cada unidade experimental, assim foram coletados os dados referentes as variáveis resposta: número de hastes por planta (NH), obtida a partir da contagem das hastes ao nível do solo; altura da primeira ramificação (APR), mensurada a partir da medição em metros, com trena, do nível do solo até o ponto da primeira ramificação; altura de plantas (AP), medida em metros, com trena, a partir do nível do solo até a extremidade mais alta da planta.

Após a colheita das raízes, foram aferidas as características: comprimento de raízes $(C R)$, mensurado pela média do comprimento, em centímetro, com trena, em 10 raízes colhidas na área útil de cada unidade experimental; diâmetro das raízes (DR), obtido através da média do diâmetro das 05 raízes, medida na parte mediana das raízes com auxílio de um paquímetro digital; massa fresca das raízes (MFR), pesagem das raízes após o arranquio, com balança digital e convertida para hectare; massa fresca da parte aérea sem cepa (MFPA), parte aérea da planta pesada, com balança digital, após a colheita e convertida para hectare; Índice de colheita (IC), avaliou-se o índice de colheita pela relação expressa em \%, entre o peso das raízes tuberosas e o peso total da planta: formula utilizada IC: $\frac{\text { Peso fresco das raízes tuberosas }}{\text { Peso total da planta }} * 100$; Tempo de cozimento, realizada na safra 2016/2017 após a colheita, foram utilizadas três amostras de raízes de cada cultivar, com tamanho de $5 \times 5 \mathrm{~cm}$ e colocados em um recipiente com um litro de água e levado ao fogo. Após 60 segundos iniciouse a avaliação, com uma haste de metal pontiaguda e sendo repetida a avaliação com intervalos de 20 segundos, até transpassarem as amostras.

Os dados foram submetidos à análise de variância e as médias foram agrupadas pelo método Scott - Knott. Todas as análises estatísticas foram realizadas com auxílio do programa Rbio (BHERING, 2017) e AgroEstat (BARBOSA; MALDONADO JUNIOR, 2015).

O coeficiente de correlação foi realizado utilizando o programa estatístico Rbio, onde foi gerada a matriz de correlação no qual foi verificado o nível de significância das variáveis. Sendo assim, foram compilados os dados das variáveis significativas, considerando de $5 \%$ e $1 \%$ nível de significância. Com os valores das variáveis ajustados de acordo com a significância, foi gerado o gráfico da rede de correlação.

\section{Resultados e Discussão}

O resumo da análise de variância revelou que houve interação significativa entre cultivares e safras para as variáveis massa fresca de raízes, massa fresca da parte aérea e índice de colheita (Tabela 2). Para as demais variáveis não houve interação, apenas efeito isolado para o fator safra, como altura de plantas, número de raiz por planta e comprimento de raiz. Para o fator cultivar houve efeito para os caracteres diâmetro de haste, altura da primeira ramificação, altura de plantas, número de raiz por planta, comprimento de raiz e diâmetro de raízes. 
Tabela 2. Resumo da análise de variância e coeficiente de variação, quanto aos caracteres número de hastes por planta $(\mathrm{NH})$, diâmetro de hastes $(\mathrm{DH})$, altura da primeira ramificação (APR), altura de plantas $(A P)$, número de raiz por planta (NRP), cumprimento de raiz $-C R$, diâmetro de raiz (DR), massa fresca de raízes (MFR), massa fresca da parte aérea (MFPA) e índice de colheita (IC), avaliados em seis cultivares de mandioca de mesa nas safras 2016/2017, 2017/2018, Jataí-GO

\begin{tabular}{ccccccccccc}
\hline \multicolumn{10}{c}{ PROBABILIDADE $(p<0,05)$} \\
\hline F.V & NH & DH & APR & AP & NRP & CR & DR & MFR & MFPA & IC (\%) \\
\hline Blocos & 0,80 & 0,42 & 0,69 & 0,12 & 0,77 & 0,32 & 0,58 & 0,64 & 0,27 & 0,75 \\
Cultivar & 0,12 & 0,00 & 0,00 & 0,00 & 0,01 & 0,00 & 0,00 & 0,00 & 0,00 & 0,00 \\
Safra & 0,98 & 0,19 & 0,57 & 0,00 & 0,00 & 0,00 & 0,00 & 0,20 & 0,00 & 0,00 \\
C $\times$ S & $0,1^{\text {ns }}$ & $0,09^{\text {ns }}$ & $0,64^{\text {ns }}$ & $0,20^{\text {ns }}$ & $0,11^{\text {ns }}$ & $0,06^{\text {ns }}$ & $0,28^{\text {ns }}$ & $0,03^{*}$ & $0,00^{*}$ & $0,05^{*}$ \\
\hline CV\% & 28,07 & 8,93 & 21,78 & 7,88 & 29,86 & 8,52 & 8,82 & 13,65 & 12,19 & 6,56 \\
\hline
\end{tabular}

ns e * para não significativo e significativo, respectivamente.

Para as variáveis número de raízes por planta e diâmetro de raízes a divisão em dois grupos, onde se destacam as cultivares BRS 397, BRS 398, BRS 399 que pertencem ao grupo que apresentaram maior número e diâmetro de raízes, com médias de 7,87 unidades por planta e $5,52 \mathrm{~cm}$, respectivamente (Tabela 3 ).

O número de raízes por planta está ligado genótipo de cada cultivar, podendo também ser afetado pela densidade de plantas por hectare, em que a maior competição entre plantas tende a promover redução no número de raízes. Em estudos com plantas de mandioca submetidas à menor competição, Aguiar et al. (2011) obtiveram maior produção de raízes. Por sua vez, em trabalho desenvolvido por Irolivea et al. (1998) avaliando três cultivares de mandioca (SRT 59, IAC $\quad 576-70$ e IAC 1287) em diferentes espaçamentos de plantio, constatou-se que para a cultivar IAC 1287 quando foi aumentado o espaçamento entre plantas, ocorreu redução na produção de raízes, comportamento diferente ao observado para as demais cultivares.

Em condições de Cerrado o processo de expansão das raízes de reserva inicia-se no período chuvoso, sendo suprida adequadamente a necessidade de água e somada com o alto índice de área foliar (FIALHO; VIEIRA, 2013). Morales (2015) avaliou em Pelotas-RS, 53 genótipos de mandioca de mesa produzidos em sistema orgânico e notou que os genótipos que apresentaram maiores quantidades de raízes tendem a ter menor comprimento e/ou diâmetro.

Tabela 3. Agrupamento de médias dos componentes de produtividade, número de raízes por planta (NRP), comprimento de raízes (CR) e diâmetro de raízes (DR) das cultivares nas safras 2016/2017 e 2017/2018, Jataí-GO

\begin{tabular}{cccc}
\hline \multirow{2}{*}{ Cultivares } & \multicolumn{3}{c}{ Variáveis } \\
\cline { 2 - 4 } & NRP & CR $(\mathrm{cm})$ & DR $(\mathrm{cm})$ \\
\hline BRS- 397 & $7,66 \mathrm{a}$ & $35,91 \mathrm{~b}$ & $5,34 \mathrm{a}$ \\
BRS- 398 & $7,31 \mathrm{a}$ & $32,83 \mathrm{~b}$ & $5,75 \mathrm{a}$ \\
BRS- 399 & $8,63 \mathrm{a}$ & $37,23 \mathrm{~b}$ & $5,46 \mathrm{a}$ \\
BRS- 400 & $5,86 \mathrm{~b}$ & $42,53 \mathrm{a}$ & $5,16 \mathrm{~b}$ \\
BRS- 401 & $4,65 \mathrm{~b}$ & $35,13 \mathrm{~b}$ & $4,71 \mathrm{~b}$ \\
IAC- 576/70 & $5,04 \mathrm{~b}$ & $37,85 \mathrm{~b}$ & $4,91 \mathrm{~b}$ \\
\hline
\end{tabular}

Médias seguidas pela mesma letra pertencem ao mesmo grupo, pelo método de agrupamento de médias de ScottKnott a $5 \%$ de probabilidade. 
Os caracteres morfológicos avaliados $\mathrm{NH}$, DH, APR e AP têm grande importância para seleção de variedades por estarem intimamente relacionados com a arquitetura da planta, afetando os tratos culturais e colheita, sendo que uma planta muito ramificada e com altura da primeira ramificação muito próxima ao solo dificulta a entrada de maquinários.

Para variável NH houve agrupamento em um único grupo de cultivares, apresentando média geral de 2,12 hastes por planta (Tabela 4). Nesse contexto, Enyi (1972) comparando quantidades de hastes entre plantas, notou que houve influência desta característica sobre a produtividade de raízes, provavelmente devido à partição de assimilados. No presente trabalho observou que o $\mathrm{NH}$ tem correlação positiva e significativa $(r=0,34)$ com o NRP (Figura 2 e Tabela 6), demonstrando que o mesmo pode influenciar sobre a definição do número de raízes fibrosas, refletindo no número de raízes de reservas. A média de hastes que o genótipo apresenta é importante para implantação e condução do plantio. Genótipos com apenas uma haste e não ramifica podem ser plantadas em menores espaçamentos, o que resulta no rendimento e redução do tempo de fechamento da cultura na linha e entrelinhas (IROLIVEA et al.,1998).

As plantas de mandioca são propagadas por meio de pedaços do caule e o diâmetro do caule está relacionada, entre outros, com a qualidade das manivas-sementes (GUIMARÃES et al., 2017). No presente estudo a variável DH apresentou dois grupos, o primeiro, com as menores médias de diâmetro, compôs-se pelas cultivares BRS 397, IAC 576/70 e BRS 398 e o grupo com os maiores valores foi formado pelas cultivares BRS 399, BRS 401 e BRS 400 (Tabela 4).

As cultivares BRS 398, BRS 399, BRS 401 e a IAC 576/70 apresentaram APR média de 58,44 $\mathrm{cm}$, sendo o grupo com maior altura da primeira ramificação (Tabela 4). Para o componente AP houve divisão em três grupos de cultivares: BRS 397, BRS 398 e a IAC 576/70 de porte baixo; BRS 399 e BRS 400 de porte médio e a cultivar BRS 401, de forma isolada, com maior porte de plantas (Tabela 4).

Segundo Távora et al. (1995) a maior taxa de crescimento das hastes ocorre no período de 90 a 180 dias após o plantio. Esse período está compreendido por meses mais chuvosos e maior fotoperíodo do ano, proporcionando maior acumulo de massa seca, sendo esses caracteres fundamentais para o cultivo, estando relacionados à facilidade de tratos culturais, ao plantio mecanizado e à colheita (FUKUDA et al., 2002; FIALHO; VIEIRA, 2013).

Tabela 4. Agrupamento de médias dos componentes biométricos, número de hastes por planta ( $\mathrm{NH})$, diâmetro de hastes (DH), altura da primeira ramificação (APR), altura de plantas (AP) das cultivares dos anos agrícolas 2016/2017 e 2017/2018, Jataí-GO

\begin{tabular}{lcccc}
\hline Cultivares & $\mathrm{NH}$ & $\mathrm{DH}(\mathrm{mm})$ & APR $(\mathrm{cm})$ & AP $(\mathrm{m})$ \\
\hline BRS-397 & $2,61 \mathrm{a}$ & $22,72 \mathrm{~b}$ & $35,59 \mathrm{~b}$ & $1,64 \mathrm{c}$ \\
BRS-398 & $1,80 \mathrm{a}$ & $25,55 \mathrm{~b}$ & $52,95 \mathrm{a}$ & $1,74 \mathrm{c}$ \\
BRS-399 & $2,08 \mathrm{a}$ & $27,53 \mathrm{a}$ & $68,55 \mathrm{a}$ & $2,09 \mathrm{~b}$ \\
BRS-400 & $1,76 \mathrm{a}$ & $29,65 \mathrm{a}$ & $35,41 \mathrm{~b}$ & $2,19 \mathrm{~b}$ \\
BRS-401 & $2,44 \mathrm{a}$ & $28,73 \mathrm{a}$ & $59,04 \mathrm{a}$ & $2,33 \mathrm{a}$ \\
IAC-576/70 & $2,05 \mathrm{a}$ & $24,27 \mathrm{~b}$ & $53,25 \mathrm{a}$ & $1,67 \mathrm{c}$ \\
\hline
\end{tabular}

Médias seguidas pela mesma letra pertencem ao mesmo grupo, pelo método de agrupamento de médias de ScottKnott a $5 \%$ de probabilidade.

A produção de massa fresca de raízes nas duas safras foi separada em três grupos de cultivares, sendo a cultivar BRS 399 pertencente ao melhor grupo, com produtividade acima de 58 $\mathrm{Mg} \mathrm{ha}{ }^{-1}$. Outras duas cultivares apresentaram mudanças de grupos de uma safra para outra, a cultivar BRS 398 que diminuiu sua produtividade e a BRS 400 aumentando o rendimento (Tabela $5)$.

Vieira et al. (2009), estudando o comportamento de 11 acessos de mandioca de mesa em seis locais no Distrito Federal por dois anos de cultivo, observaram que em apenas um dos locais houve influência do fator safra sobre a 
produtividade de raízes. Por sua vez, Vieira et al. (2015), analisaram oito acessos de mandioca de mesa na região do Cerrado em Unaí-MG, em duas safras e notaram que o coeficiente safra influenciou na produção de raízes.

Desdobrando os resultados de massa fresca da parte aérea, o grupo das cultivares BRS 399, BRS 401 e BRS 400 apresentaram maiores produções dentro da safra 2016/2017. Por sua vez, na safra 2017/2018 a BRS 400 apresentou maior produção de parte aérea, seguida por dois grupos de cultivares (Tabela 5). Comparando a massa fresca da parte aérea das duas safras, a safra 2017/2018 apresenta resultados superiores a safra 2016/2017, onde as cultivares BRS 399, BRS 400, BRS 401 e IAC 576/70 aumentaram a produção de massa da parte aérea (Tabela 5).

Estes resultados corroboram os de Tironi et al. (2015) e Silva et al. (2014), no primeiro, os autores avaliaram o desempenho agronômico de cinco cultivares de mandioca por dois anos agrícolas em Santa Maria, RS, onde foi observado que o fator safra influenciou a produção de massa seca da parte aérea, com diminuição de
$34,10 \%$ da primeira para segunda safra. No segundo trabalho, os autores avaliaram treze acessos de mandioca em Planaltina-DF, e revelaram a existência de interação entre acessos $x$ safras para massa da parte aérea. De forma análoga, Fuhrmann (2015) também detectou a presença de interação entre os fatores safra e genótipos para a caraterística massa da parte aérea em estudo conduzido na região do cerrado do Distrito Federal, indicando que a média desses caracteres foi influenciada pelo fator safra.

Para Alves (2006) o índice de colheita pode ser usado como critério de seleção para maiores rendimentos em mandioca, sendo considerados os valores satisfatórios acima de $50 \%$ (Peixoto et al., 2005). Nesta pesquisa, a variável índice de colheita apresentou valores acima de $50 \%$ para todos os cultivares na safra 2016/2017, entretanto, na safra de 2017/2018, as cultivares BRS 400 e BRS 401 ficaram abaixo do índice ideal (Tabela 5).

Tabela 5. Agrupamento de médias da massa fresca de raízes (MFR), massa fresca da parte aérea (MFPA) e índice de colheita (IC) dos anos agrícolas 2016/2017 e 2017/2018, Jataí-GO

\begin{tabular}{ccccccc}
\hline \multirow{2}{*}{ Cultivares } & \multicolumn{2}{c}{ MFR $-M g$ ha $^{-1}$} & \multicolumn{2}{c}{ MFPA $-M g$ ha $^{-1}$} & \multicolumn{2}{c}{ IC\% } \\
& $16 / 17$ & $17 / 18$ & $16 / 17$ & $17 / 18$ & $16 / 17$ & $17 / 18$ \\
\hline BRS-397 & $38,69 \mathrm{bA}$ & $41,59 \mathrm{bA}$ & $14,08 \mathrm{bA}$ & $19,10 \mathrm{cA}$ & $65,00 \mathrm{aA}$ & $66,00 \mathrm{aA}$ \\
BRS-398 & $36,32 \mathrm{bA}$ & $29,65 \mathrm{cA}$ & $16,80 \mathrm{bA}$ & $17,36 \mathrm{cA}$ & $60,00 \mathrm{aA}$ & $63,00 \mathrm{aA}$ \\
BRS-399 & $58,02 \mathrm{aA}$ & $58,84 \mathrm{aA}$ & $25,21 \mathrm{aB}$ & $33,16 \mathrm{bA}$ & $60,00 \mathrm{aA}$ & $58,00 \mathrm{bA}$ \\
BRS-400 & $27,82 \mathrm{cB}$ & $46,25 \mathrm{bA}$ & $20,87 \mathrm{aB}$ & $53,99 \mathrm{aA}$ & $52,00 \mathrm{bA}$ & $43,00 \mathrm{cB}$ \\
BRS-401 & $27,93 \mathrm{cA}$ & $25,52 \mathrm{cA}$ & $22,63 \mathrm{aB}$ & $33,12 \mathrm{bA}$ & $51,00 \mathrm{bA}$ & $41,00 \mathrm{cB}$ \\
IAC-576/70 & $31,43 \mathrm{cA}$ & $35,31 \mathrm{cA}$ & $13,95 \mathrm{bB}$ & $20,83 \mathrm{cA}$ & $68,00 \mathrm{aA}$ & $62,00 \mathrm{aB}$ \\
\hline
\end{tabular}

Médias seguidas pela mesma letra pertencem ao mesmo grupo, minúsculas nas colunas, maiúsculas nas linhas, pelo método de agrupamento de médias de Scott-Knott a 5\% de probabilidade.

De acordo com a análise do coeficiente de correlação (Tabela 6) e a rede de correlação (Figura 2), a variável MFR possui correlação positiva com os componentes MFPA, NRP e IC, evidenciando que a parte aérea da planta influencia na quantidade de raízes e evidencia o IC. Para o componente MFR existirá correlação positiva até certo ponto com a MFPA, pois essa ligação resulta no equilíbrio da partição de assimilados, sendo que o IC correlaciona positivamente para MFR e negativamente MFPA.

Os componentes AP e DH correspondem a MFPA, pois possuem positivas correlações, que demonstram a importância do desenvolvimento da parte aérea da planta. Já o DR correspondeu negativamente com MFPA, sendo justificado por algumas cultivares apresentarem alto desenvolvimento vegetativo da parte aérea (Figura 2 e Tabela 6). Vieira et al. (2014), avaliando características agronômicas de mandioca de propagações vegetativa e sexual, obtiveram correlação significância entre a massa de raízes e a massa da parte aérea, e da massa da parte aérea com a altura da planta. 
Tabela 6. Coeficiente de correlação das variáveis número de raízes por planta (NRP), comprimento de raízes (CR), diâmetro de raízes (DR), massa fresca de raízes (MFR), número de hastes por planta (NH), diâmetro de hastes (DH), altura da primeira ramificação (APR), altura de plantas (AP) e massa fresca da parte aérea (MFPA). Anos agrícolas 2016/2017 e 2017/2018, Jataí-GO

\begin{tabular}{ccccccccccc}
\hline & MFR & MFPA & IC & NH & NRP & CR & DR & DH & AP & APR \\
\hline MFPA & $0,36^{*}$ & 1 & & & & & & & & \\
IC & $0,43^{* *}$ & $-061^{* *}$ & 1 & & & & & & \\
NH & $-0,12^{\text {ns }}$ & $-0,32^{\text {ns }}$ & $0,13^{\text {ns }}$ & 1 & & & & & \\
NRP & $0,36^{*}$ & $-0,00^{\text {ns }}$ & $0,22^{\text {ns }}$ & $0,34^{*}$ & 1 & & & & \\
CR & $-0,01^{\text {ns }}$ & $0,10^{\text {ns }}$ & $0,02^{\text {ns }}$ & $-0,07^{\text {ns }}$ & $-0,15^{\text {ns }}$ & 1 & & & \\
DR & $0,20^{\text {ns }}$ & $-0,33^{*}$ & $0,39^{*}$ & $-0,13^{\text {ns }}$ & $0,00^{\text {ns }}$ & $0,07^{\text {ns }}$ & 1 & & \\
DH & $0,00^{\text {ns }}$ & $0,48^{* *}$ & $-0,40^{* *}$ & $-0,31^{\text {ns }}$ & $-0,05^{\text {ns }}$ & $0,38^{*}$ & $-0,10^{\text {ns }}$ & 1 & \\
AP & $-0,08^{\text {ns }}$ & $0,35^{*}$ & $-0,50^{* *}$ & $0,07^{\text {ns }}$ & $-0,04^{\text {ns }}$ & $0,33^{*}$ & $-0,10^{\text {ns }}$ & $0,74^{* *}$ & 1 & \\
APR & $0,16^{\text {ns }}$ & $-0,01^{\text {ns }}$ & $-0,03^{\text {ns }}$ & $0,24^{\text {ns }}$ & $0,31^{\text {ns }}$ & $-0,21^{\text {ns }}$ & $-0,03^{\text {ns }}$ & $0,11^{\text {ns }}$ & $0,30^{\text {ns }}$ & 1 \\
\hline
\end{tabular}

*significativo a $5 \%$; ${ }^{* *}$ significativo a $1 \%$

Figura 2. Rede de correlação de variáveis número de raízes por planta (NRP), comprimento de raízes (CR), diâmetro de raízes (DR), massa fresca de raízes (MFR), número de hastes por planta (NH), diâmetro de hastes (DH), altura da primeira ramificação (APR), altura de plantas (AP) e massa fresca da parte aérea (MFPA). Linhas vermelhas e verdes representam negativo e correlações positivas, respectivamente. A intencidade da cor da linha é proporcional à força da correlação. Anos agrícolas 2016/2017 e 2017/2018, Jataí-GO

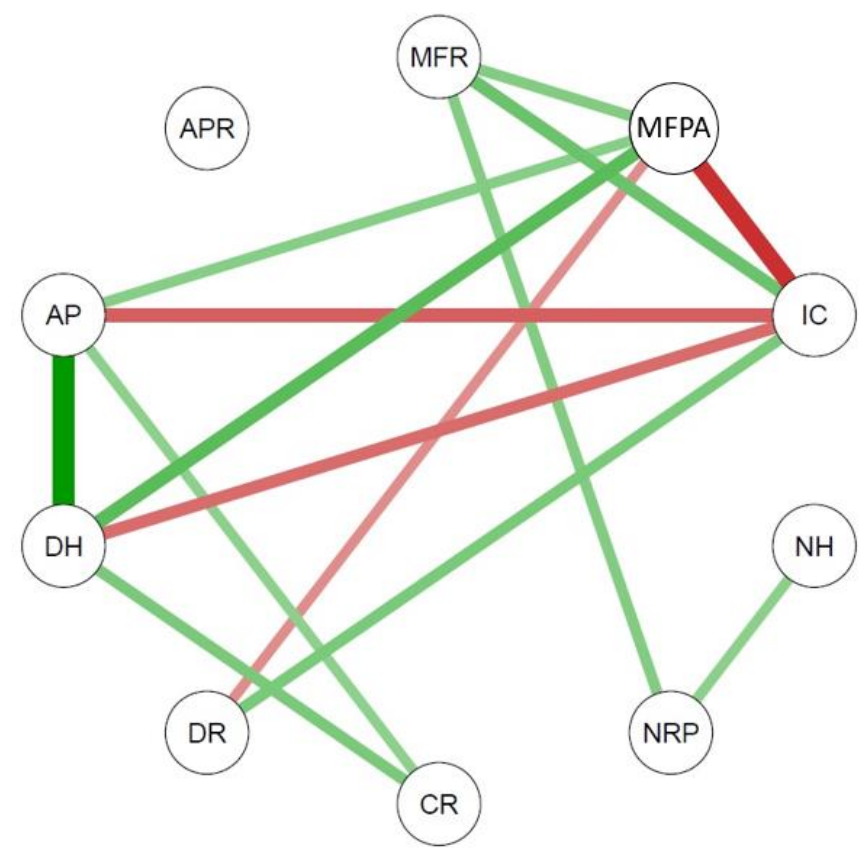

O tempo de cozimento das cultivares colhidas aos nove meses de cultivo no ano agrícola de 2016/2017 apresentaram 256 a 665 segundos para a cocção (Tabela 7). Portanto, este baixo tempo de cozimento pode ser explicado pela precocidade da colheita dessas variedades de mandioca de mesa. Rinaldi et al. (2017) consideram o tempo máximo aceitável para a cocção de raízes de mandioca de mesa como sendo 30 minutos, sendo assim, todas possuem caráter positivo para mandioca de mesa. É oportuno ressaltar que o rápido cozimento de mandioca de mesa também se associa à textura macia das raízes tuberosas (SCHALLENBERGER et al., 2016). 
Tabela 7. Agrupamento de médias do tempo de cozimento em segundos de sete cultivares avaliadas na safra 2016/2017, em Jataí-GO

\begin{tabular}{cc}
\hline Cultivares & Tempo de Cozimento (seg.) \\
\hline BRS 397 & $256 \mathrm{a}$ \\
BRS 398 & $369 \mathrm{a}$ \\
BRS 399 & $390 \mathrm{a}$ \\
BRS 400 & $501 \mathrm{~b}$ \\
BRS 401 & $665 \mathrm{~b}$ \\
IAC576/70 & $422 \mathrm{a}$ \\
\hline Probabilidade $(p<0,05)$ & 0,0013 \\
\hline CV\% & 27,14 \\
\hline
\end{tabular}

Médias seguidas pela mesma letra pertencem ao mesmo grupo, pelo método de agrupamento de médias de ScottKnott a $5 \%$ de probabilidade.

Por ser encontrada em grande área, com diferentes condições edafoclimáticas, a cultura da mandioca é submetida a amplas variações de temperatura, fotoperíodo, radiação solar e chuva (ALVES, 2006). A princípio, a oferta pluviométrica é um dos fatores com maior importância para a produção de mandioca, necessitando de um regime de chuvas bem distribuídos e compreendido de um total anual entre $1000 \mathrm{~mm}$ e $1500 \mathrm{~mm}$ (SILVA et al., 2017). Segundo Alves (2006), as fases de desenvolvimento dependem de vários fatores pertinentes a diferenças varietais, condições ambientais e práticas culturais. Portanto, esses resultados estão condizentes a maior precipitação na safra $2017 / 2018$ de $1680,5 \mathrm{~mm}$, ante os $1324,8 \mathrm{~mm}$ da safra 2016/2017, com melhor distribuição das chuvas no decorrer do ano agrícola 2017/2018 (Figura 1).

\section{Conclusões}

Dentro das condições do presente estudo, todas as cultivares de mandioca de mesa avaliada apresentaram rendimento satisfatório de raízes tuberosas. As cultivares BRS 397, BRS 398, BRS 399 e IAC 576/70 apresentaram melhor desempenho agronômico no ano agrícola 2016/2017, por sua vez, no ano agrícola 2017/2018 as cultivares BRS 397, BRS 399 e BRS 400 apresentaram os melhores resultados. Ressalta-se ainda que as cultivares BRS-397 e BRS-399 apresentaram desempenho agronômico mais estável que as demais nas duas safras em que o experimento foi avaliado.

\section{Referências}

AGUIAR, E. B.; VALLE, T. L.; LORENZI, J. O.; KANTHACK, R. A. D.; MIRANDA FILHO, H.;
GRANJA, N. P. Efeito da densidade populacional e época de colheita na produção de raízes de mandioca de mesa. Bragantia, Campinas, v.70, n.3, p.561-569, 2011. http://dx.doi.org/10.1590/S0006$\underline{87052011005000010}$

AGUIAR, J. L. P.; SOUSA, T. C.; LÔBO, C. F. Aspectos econômicos e de mercado do cultivo de mandioca. In: FIALHO, J. F.; VIEIRA, E. A. (Ed.). Mandioca no Cerrado: orientações técnicas. 2. ed. Planaltina: Embrapa, 2013. p. 161-203. Disponivel em: http://www.infoteca.cnptia.embrapa.br/infoteca /handle/doc/981357. Acesso em: 20 mar. 2019.

ALVES, A. A. C. Fisiologia da mandioca. In: SOUZA, L. S.; FARIAS, A. R.; MATTOS, P. L. P.; FUKUDA, W. M. G. (Ed.). Aspectos socioeconómicos e agronômicos da mandioca. Cruz das Almas: Embrapa Mandioca e Fruticultura Tropical, 2006. p. 138-169.

BARBOSA, J. C.; MALDONADO JUNIOR, W. AgroEstat - Sistema para análises estatísticas de ensaios agronômicos. Jaboticabal: UNESP. 2015.

BHERING, L. L. A tool for biometric and statistical analysis using the $\mathrm{R}$ platform. Crop Breeding and Applied Biotechnology, Viçosa, v.17, n.2, p. 187190, 2017. https://doi.org/10.1590/198470332017v17n2s29

CARDOSO, M. R. D.; MARCUZZO, F. F. N.; BARROS, J. R. Classificação climática de köppengeiger para o estado de Goiás e o Distrito Federal. ACTA Geográfica, v.8, n.16, p.40-55, 2015. http://dx.doi.org/10.5654/actageo2014.0004.0016 
CONAB. Conjuntura mensal: mandioca: raiz, farinha e fécula. Brasília, 2017. 9p. Disponível em: https://www.conab.gov.br/info-agro/analises-domercado-agropecuario-e-extrativista/analises-domercado/historico-mensal-demandioca/item/download/15259 56be85ab112f a621766e44d32e7154f7Acesso em: 09 mar. 2019.

EMBRAPA CERRADOS. Embrapa lança cultivares de mandioca de mesa. Planaltina: Embrapa Cerrados, 2016. Disponível em: https://www.embrapa.br/busca-de-noticias//noticia/6252350/embrapa-lanca-cultivares-demandioca-de-mesa. Acesso em: 15 mar. 2019.

ENYI, B.A.C. Efeito do número de brotações e do tempo de plantio no crescimento, desenvolvimento e produtividade da mandioca (Manihot esculenta Crantz). Journal of Horticultural Science, v.47, p.457-466, 1972. http://dx.doi.org/10.1080/

$\underline{00221589.1972 .11514489}$

FAO. Cassava. Statistics Division, 2020. Disponível em:

http://www.fao.org/faostat/en/\#data/QC/visuali ze. Acesso em: 9 abr. 2020.

FIALHO, J. F.; VIEIRA, E. A. Manejo e tratos culturais da mandioca. In: FIALHO, J. F.; VIEIRA, E. A. (Ed.). Mandioca no cerrado: orientações técnicas. 2.ed. Brasilia: Embrapa, 2013. p.61-88.

FIALHO, J. F.; VIEIRA, E. A.; SILVA, M. S.; PAULA, M. S. V, FUKUDA W. M. G.; SANTOS FILHO, M. O. S.; SILVA, K. N. Desempenho de variedades de mandioca de mesa no Distrito Federal. Revista Brasileira de Agrociência, v.15, n.1-4, p.31-35, 2009. http://dx.doi.org/10.18539/cast.v15i14.1983

FUHRMANN, E. Caracteres morfo-agronômicos e bioquímicos de clones elite de mandioca de mesa com raízes de polpas amarelada e rosada. 2015. Tese (Doutorado em Agronomia) Universidade de Brasília, Brasília, 2015.

FUKUDA, W. M. G.; SILVA, S. O.; IGLESIAS, C. Cassava breeding. Crop Breeding and Applied Biotechnology. Viçosa, v.2, n.4, p.617-638, 2002. http://dx.doi.org/10.12702/1984-

7033.v02n04a18
GUIMARÃES, D. G.; PRATES, C. J. N.; VIANA, A. E. S.; CARDOSO, A. D.; TEIXEIRA, P. R. G.; CARVALHO, K. D. Caracterização morfológica de genótipos de mandioca (Manihot esculenta Crantz). Scientia Plena, v.13, n.9, p.1-11, 2017. http://dx.doi.org/10.14808/sci.plena.2017.09020 1

IROLIVEA, E.A.M.; CAMARA, G.M.S.; NOGUEIRA, M.C.S.; CINTRA, H.S. Efeito do espaçamento entre plantas e da arquitetura varietal no comportamento vegetativo e produtivo da mandioca. Scientia Agricola, v.55, n.2, p.269-275, $1998 . \quad$ http://dx.doi.org/10.1590/S010390161998000200016

MORALES, C. F. G. Avaliação do desempenho agronômico e culinário de genótipos de mandioca (Manihot esculenta Crantz) em Pelotas, RS e Cruz das Almas, BA, 2015. Tese (Doutorado em Agronomia) - Universidade Federal de Pelotas, Pelotas, 2015.

PEIXOTO, J. R.; BERNARDES, S. R.; SANTOS, C. M.; BONNAS, D. S.; FIALHO, J. F. Desempenho agronômico de variedades de mandioca mansa em Uberlândia, MG. Revista Brasileira de Mandioca, v.18, p.19-24, 2005.

REINHARDT, D. H. R. Mandioca - a raiz do Brasil "O pão do Brasil". Um símbolo da identidade cultural brasileira. Cruz das Almas: Embrapa Mandioca e Fruticultura, 2013. Disponível em: http://www2.camara.leg.br/atividade-

legislativa/comissoes /comissoespermanentes/capadr/audiencias-

publicas/audiencias-publicas-2013/audienciapublica-16-de-abril-de-2013-embrapa-mandioca. Acesso em: 04 abr. 2018.

RINALDI, M. M.; FIALHO, J. D. F.; VIEIRA, E. A.; OLIVEIRA, T. A. R.; ASSIS, S. D. O. Utilização de ácido cítrico para a conservação pós-colheita de raízes de mandioca. Brazilian Journal of Food Technology, Campinas, v.20, e2017072, 2017. http://dx.doi.org/10.1590/1981-6723.07217

RINALDI, M. M.; VIEIRA, E. A.; FIALHO, J. D. F.; MALAQUIAS, J. V. Efeito de diferentes formas de congelamento sobre raízes de mandioca. Brazilian Journal of Food Technology, Campinas, v.18, n.2, p.93-101. 2015. https://dx.doi.org/10.1590/1981-6723.3414 
SANTOS, H. G.; JACOMINE, P. K. T.; ANJOS, L. H. C.; OLIVEIRA, V. A.; LUMBRERAS, J. F.; COELHO, M. R.; ALMEIDA, J. A.; ARAUJO FILHO, J. C.; CUNHA, T. J. F.; OLIVEIRA, J. B. Sistema Brasileiro de Classificação de Solos. 5. ed. Brasília: Livro técnico (INFOTECA-E), 2018. E-book. Disponível em

http://www.infoteca.cnptia.embrapa.br/infoteca /handle/doc/1094003. Acesso em: 21 set. 2018.

SARAVANAN, R.; RAVI, V.; STEPHEN, R.; THAJUDHIN, S.; GEORGE, J. Post-harvest physiological deterioration of cassava (Manihot esculenta) - a review. Indian Journal of Agricultural Sciences, v.86, n.11, p.1383-1390, 2016.

SCHALLENBERGER, E.; REBELO, J.; CANTÚ, R.; MORALES, R.; NEUBERT, E; MORETO, A. Novas cultivares de aipim: SCS256 Seleto, SCS257 Estação EEI, SCS 258 Peticinho e SCS259 Diamante. Agropecuária Catarinense, v.29, n.1, p.58-62, 2016.

SILVA, F. A. M.; FIALHO, J. F.; CORREIA, J. R.; VIEIRA, E. A. Aspectos Edafoclimáticos. In: FIALHO, J. F.; VIEIRA, E. A.; BORGES, A. L. (Ed.). Cultivo da mandioca para região do cerrado. Planaltina: Embrapa Cerrados, 2017. p. 8-15. Disponível em: http://ainfo.cnptia.embrapa.br/digital/bitstream/ item/167777/1/Cultivo-da-Mandioca-paraRegiao-do-Cerrado.pdf. Acesso em: 20 set. 2018.

SILVA, K. N.; VIEIRA, E. A.; FIALHO, J. F.; CARVALHO, L. J. C. B.; SILVA, M. S. Potencial agronômico e teor de carotenoides em raízes de reserva de mandioca. Ciência Rural, v.44, n.8, p.1348-1354, 2014.

https://dx.doi.org/10.1590/0103$\underline{8478 \mathrm{cr} 20130606}$

SOUSA, D. M. G.; FIALHO, J. F.; SANTOS JÚNIOR, J. D. G.; REIN, T. A.; VIEIRA, E. A. Calagem e adubação. In: FIALHO, J. F.; VIEIRA, E. A.; BORGES, A. L. (Ed.). Cultivo da mandioca para região do cerrado. Planaltina:Embrapa Cerrados, 2017. p. 8-15. Disponível em: http://ainfo.cnptia.embrapa.br/digital/bitstream/ item/167777/1/Cultivo-da-Mandioca-paraRegiao-do-Cerrado.pdf. Acesso em: 20 set. 2018. SOUSA, D. M. G.; LOBATO, E. Cerrado: correção do solo e adubação. Planaltina: Embrapa Cerrados, 2004. 416 p.
TÁVORA, F.J.A.; MELO, F. I. O; PINHO, J. I. N; QUEIROZ, G. M. Produção, taxa de crescimento e capacidade assimilatória da mandioca no Litoral do Ceará. Resista Brasileira de Fisiologia Vegetal, v.7, p.81-88, 1995.

TIRONI, L. F.; UHLMANN, O. L; STRECK, N. A; SAMBORANHA, F. K. Desempenho de cultivares de mandioca em ambiente subtropical. Bragantia, Campinas, v.74, n.1, p.5866, 2015. http://dx.doi.org/10.1590/16784499.0352

VENTURINI, M. T.; SANTOS, L. R.; OLIVEIRA, E. J. Development of a diagrammatic scale for the evaluation of postharvest physiological deterioration in cassava roots. Pesquisa Agropecuária Brasileira, Brasilia, v.50, n.8, p.658668, 2015. http://dx.doi.org/10.1590/50100$\underline{204 \times 2015000800004}$

VIEIRA, E. A.; FIALHO, J. F.; CARVALHO, L. J. C. Correlação fenotípica entre caracteres agronômicos em população segregante de mandioca de mesa. Revista Ceres, Viçosa, v.61, n.4, p.523-529, 2014.

https://doi.org/10.1590/0034737X201461040011

VIEIRA, E. A.; FIALHO, J. F.; JULIO, L.; CARVALHO, L. J. C. B.; DALLA CORTE, J. L.; RINALDI, M. M.; OLIVEIRA, C. M.; FERNANDES, F. D.; ANJOS, J. R. $N$. Sweet cassava cultivars with yellow or cream root pulp developed by participatory breeding. Crop Breeding and Applied

Biotechnology, v.18, n.4, p.450-454, 2018.

http://dx.doi.org/10.1590/1984-

70332018v18n4c67

VIEIRA, E. A.; FIALHO, J. F; SILVA, M. S.; FUKUDA, W. M. G.; SANTOS FILHO, M. O. S; Comportamento de genótipos de mandioca de mesa no Distrito Federal. Revista Ciência Agronômica, v.40, n. 1, p.113-122, 2009.

VIEIRA, E. A.; FREITAS, J.; CARVALHO, L. J. C. B.; MALAQUIAS, J. V.; FERNANDES, F. D. Desempenho agronômico de acessos de mandioca de mesa em área de Cerrado no município de Unaí, região noroeste de Minas Gerais. Científica, v.43, n.4, p.371-377, 2015. http://dx.doi.org/10.15361/1984-

5529.2015v43n4p371-377 